\title{
Rafael Amorim> Como propor um cartão postal
}

\section{Resumo}

Escrito em primeira pessoa, o presente artigo reflete sobre a ação Como propor um cartão postal, executada na Escola de Artes Visuais do Parque Lage - Rio de Janeiro, e compreendida como um desdobramento do Programa de Formação Gratuito de 2019. O escopo da ação que carrega o mesmo título deste estudo, foi o gesto de almoçar marmitas nas dependências do palacete da Escola, entendendo-o como prática desviante no cotidiano desse lugar, que existe na fronteira entre uma escola de artes livre e um dos pontos turísticos mais visitados no Rio de Janeiro. Este texto traz não só uma narrativa sobre o que foi o trabalho proposto, mas também reflexões críticas acerca da aderência de determinados corpos e agenciamentos em espaços de arte
\end{abstract}

Palavras-chave: Performance. Escrita de artista. Práticas coletivas.

\footnotetext{
Rafael Amorim é poeta, pesquisador e curador independente. Graduado no Bacharelado em Artes Visuais/ Escultura pela Escola de Belas Artes da Universidade Federal do Rio de Janeiro, fez parte como discente do Programa de Formação Gratuito da Escola de Artes Visuais do Parque Lage - RJ (2019).
}

amorimrafael.belasartes@gmail.com

ORCID ID: 0000-0002-0914-2908 


\title{
Rafael Amorim How to propose a postcard
}

\begin{abstract}
Written in first person, the present article reflects about the performance Como propor um cartão postal (how to propose a postcard), executed at Escola de Artes Visuais do Parque Lage - Rio de Janeiro (Visual Arts School of Parque Lage) and understanded like an unfolding of its public program of 2019. The action's scopehandles the same title from this text: the gesture of lunching marmitas at the masion's space, understanding it like a deviant practice at the place's daily. Parque Lage exists at the border beetween a free art school and one of the most famous turistics points from Rio de Janeiro. This text brings not only a narrative about what was the proposed work, but also critical reflections about the adherence of certain bodies and agencies at art spaces.
\end{abstract}

Keywords: Performance. Artist's text. Collective practices. 
No mais leve movimento de uns galhos, dilata-se o mundo. Adolfo Montejo Navas

\section{De onde partir}

Durante o ano de 2019, a Escola de Artes Visuais do Parque Lage - Rio de Janeiro destinou cinquenta bolsas a estudantes em seu Programa de Formação Gratuito, visando assim contemplar o máximo de narrativas não centralizadas dentro da memória de uma cidade segregada e marcada por assimetrias socioespaciais. Nesse período de vigência do Programa, a Escola se viu habitada por discentes que representavam corpos diversos, minorias raciais, sociais e de gênero. Portanto, é possível que durante aquele período houvesse mais pessoas negras, LGBTQIA+ e periféricas ocupando simultaneamente aquele espaço do que em toda a história do Parque Lage.

Dividido em duas turmas de vinte e cinco estudantes bolsistas (popularmente identificadas durante o semestre como Formação e Deformação) ${ }^{1}$, o Programa Gratuito ofereceu àquelas narrativas, como desdobramento dos estudos em aula, duas exposições coletivas nos espaços disponibilizados pela Escola. Ambas as exposições pensadas para dezembro daquele ano a março do ano seguinte.

No entanto, ao contemplar pessoas artistas, pesquisadoras e interessadas em arte que formavam um grupo em sua maioria oriundo de zonas não centrais na cidade, certas fissuras institucionais começavam a aparecer em relação à permanência desses mesmos corpos. Dentro do primeiro mandato de um governo que pretendeu desestabilizar iniciativas culturais em todas as suas vertentes, a Escola de Artes Visuais do Parque Lage encontrava alguma dificuldade em aderir pelo menos vinte e uma dessas pessoas

1 A partir da chamada aberta e com duração de dois semestres, o Programa de Formação em Artes foi dividido em duas turmas: Emergência e Resistência e Exercício Experimental da Liberdade. A primeira tendo como principal metodologia o acompanhamento e desenvolvimento das pesquisas artísticas através de encontros de formação teórico-prática (propostos pelos professores Clarissa Diniz, Gleyce Kelly Heitor e Ulisses Carrilho), além de visitas a ateliês de artistas e encontros com professores de diferentes áreas da cultura. À segunda turma, Exercício Experimental da Liberdade, eram apresentados elementos das histórias, teorias e críticas da arte em quatro eixos ministrados pelos professores e curadores Camilla Rocha Campos, Fernanda Lopes, Fernando Cocchiarale e Keyna Eleison. 
que não contavam com auxílio para cobrir os custos referentes ao transporte e à alimentação numa instituição localizada na Zona Sul Carioca.

Endereçada à instituição e posteriormente veiculada às redes sociais, a proposta EAV PARA TODES, ${ }^{2}$ uma iniciativa autônoma que unia as duas turmas, emergia sentido à arrecadação - a partir de doações - de um valor que pudesse, pelo menos, retornar para o grupo de estudantes no fim do período letivo. De modo que o resultado fosse não só efetivo no ressarcimento dos gastos para aquele grupo de estudantes que dedicava suas rotinas a ocupar diariamente uma escola de artes no Jardim Botânico, mas que operasse mudanças na maneira como a instituição futuramente receberia e abrigaria outros grupos de narrativas dissidentes.

Diante disso, muitos dos processos que se elaboravam para as exposições coletivas pretendidas foram tocados direta e indiretamente pela constante reivindicação das pautas sobre transporte e alimentação. Desdobrando-se, então, entre muitos binômios: ausência e presença, permanência e evasão, movimento e repouso, público e privado etc.

Postal, registro da performance que produzi como trabalho a ser exposto em Como nos movemos, como queremos nos mover? ${ }^{3}$, proposta pela turma Exercício Experimental da Liberdade, veio à tona para elencar a lista de obras de uma exposição que começava a ser delineada sem muitos recursos e que pleiteava, além da verba da arrecadação, espaços físicos e simbólicos dentro das próprias camadas institucionais - o tempo inteiro em negociação.

2 Após a doação de uma obra da artista plástica lole de Freitas e de sua comercialização pela Escola na feira de arte ArtRio, foi que se garantiu o valor reivindicado pelo grupo de estudantes na arrecadação coletiva. Colaborando não só com a permanência e conclusão daquelas narrativas na EAV, como também com a repercussão dos resultados do Programa. Esse que vem sendo proposto pela gestão Parque Lage desde 2012 mas que, devido ao eventual corte de verbas em 2016, a Escola deixara de oferecer, retomando-o apenas em 2018.

3 Pensada a partir da heterogeneidade de um grupo de narrativas partilhadas ao longo da caminhada conjunta durante o ano de 2019, a exposição buscou identificar a questão da mobilidade como ponto de partida para os trabalhos. No release da exposição, Daniela Avellar, estudante responsável pelo texto reflexivo da exposição, escreve que "tanto por sua implicação prática e social, relacionada a como de fato se chega e se permanece numa escola de artes, quanto por seus desdobramentos poéticos e suas possíveis espessuras como parte da formação de cada pesquisa iniciada ou desenvolvida em aula. Trata-se de uma exposição questionamento, contendo um ponto de interrogação necessário em seu enunciado. Os trabalhos que ocupam a Galeria 1 e a Capela do Parque Lage buscam apoio uns nos outros para propor uma rede de relação entre estruturas móveis, que não deixam seus deslocamentos simbólicos estratificarem por completo pois se mostram sempre abertas à dúvida e atentas aos espaços que as rodeiam." Disponível em: <http:// eavparquelage.rj.gov.br/como-nos-movemos-como-queremos-nos-mover/> 


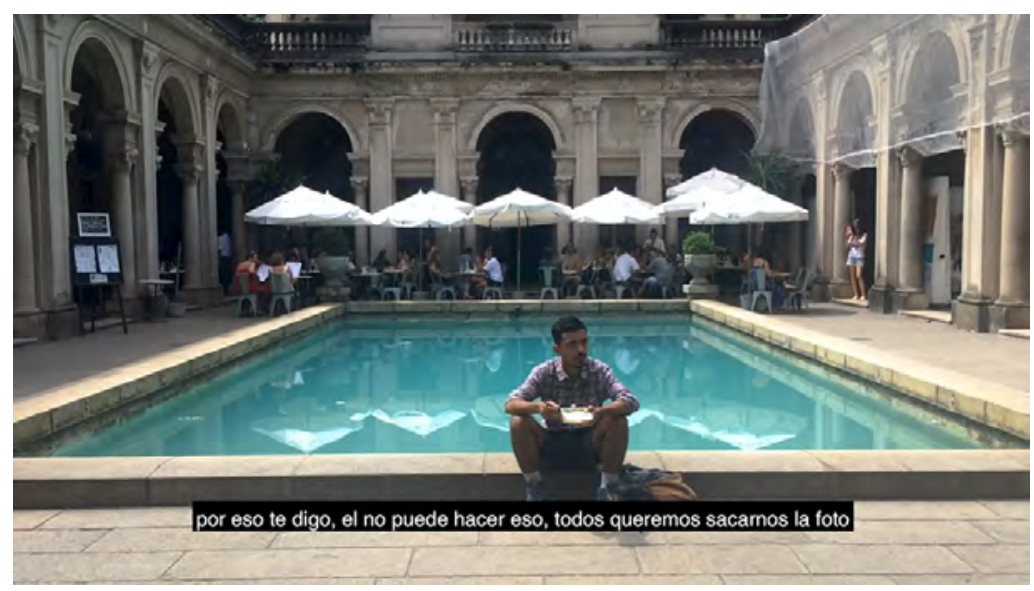

Figuras 1 e 2: Frames da obra "Postal", Rafael Amorim, 2019.

Fonte: Acervo do artista

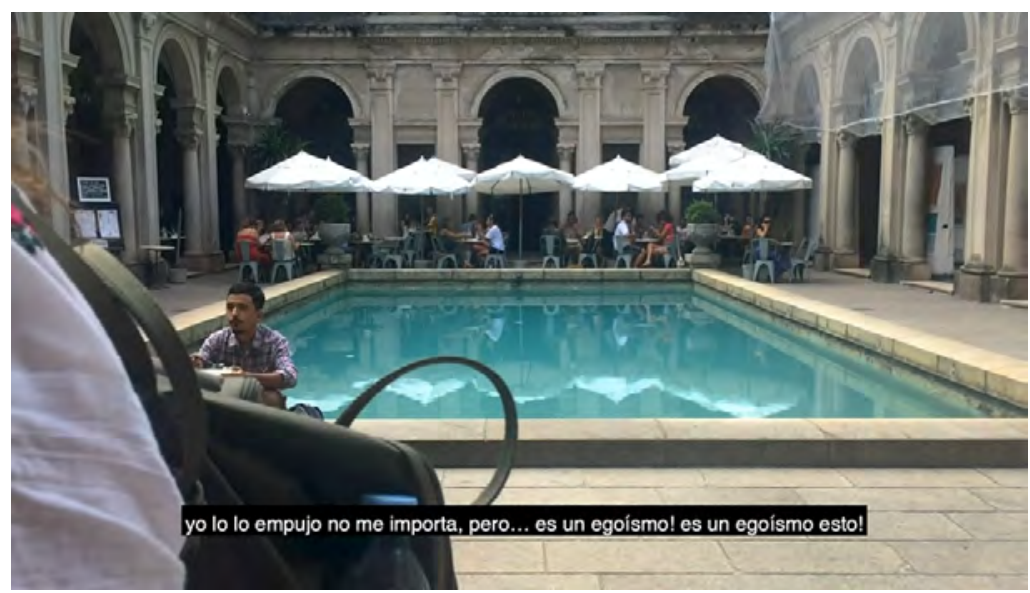

No trabalho, simulo um corpo-turístico enfrentando a extensa fila que se institucionalizou cotidianamente para a foto com a arquitetura do palacete e o Cristo Redentor enquadrados ao fundo. Uma vez posicionado frente à piscina, provoco outra maneira de habitar aquele espaço: silenciosamente e sem anunciar que ali se iniciava uma proposição artística, retiro da mochila a sacola plástica que embrulhava a marmita de comida trazida de casa.

Dado que a partitura da ação se apresentou de acordo com o tempo que levaria a ingerir aquele almoço, sua duração ainda era indeterminada. Mas foi preciso tão pouco - essa espécie de metodologia que se volta à imprevisibilidade já encalacrada ao habitar espaços em conjunto - para que o menor dos movimentos produzisse alguma fricção naquele território de fronteiras embaçadas. $\mathrm{O}$ que, então, talvez já pudesse ser esperado como um hábito (por se tratar hoje de uma escola de artes com estudantes em intensa produção) não foi muito bem recebido pelo público de turistas que ali pretendia registrar, com seus celulares, a paisagem difundida internacionalmente como cartão postal carioca.

No ápice de seu estranhamento com relação ao gesto não esperado, uma turista sentencia em espanhol que aquilo se mostrava como uma cena inadmissível, já que estaríamos todos, segundo ela, querendo a mesma coisa. Impaciente e agora descontente pelas falhas tentativas na comunicação entre nós, sugerindo até me atirar na piscina, a mesma afirma para quem quiser ouvir que: "É por esse tipo de gente que o mundo está como está" (sic).

Em quase oito minutos de duração, a ação e seu registro em vídeo acontecem sob a inconformada reação dos turistas 
presentes. Estes, retirados do conforto de suas intenções para com a paisagem e realocados sob a perspectiva de figurantes em algo da ordem do invisível. Nesse sentido, Postal pode ser percebido como uma apologia ao desconforto, por estar direcionado a um determinado perfil de público que, interessado na paisagem como ponto turístico a servir de palco para a produção em massa de imagens, parece ignorar a presença de uma escola de artes que ali existe desde a década de sessenta.

Evidentemente, ainda tentando resgatar, também, algum resquício da alcunha de Escola Livre proposta por Rubens Gerchman e sua efervescência enquanto pólo de resistência artística durante a ditatura militar, é que me vejo envolvido pelo interesse em confrontar as muitas tramas sensíveis que habitam aquele território dividido entre estudantes-artistas, professores, funcionários públicos terceirizados, turistas e parte de alguma elite da Zona Sul do Rio de Janeiro.

Interessado por essa fronteira é que sou convocado a olhar para as relações criadas por quem habita atualmente o Parque Lage, lugar historicamente marcado por um passado no Brasil Colônia, ainda perpetuado pela apropriação turística sobre diferentes territórios na cidade. Assim, provocados pela arquitetura de um palacete projetado em meio à Mata Atlântica, determinados corpos vão habitar aquele território com um único intuito: manter viva a marca de uma presente e ainda dominante aristocracia carioca.

\section{Onde chegar}

Para compor a programação durante os meses de exposição, e como tentativa de transpor a partitura performativa de Postal para o coletivo, lanço a chamada aberta Como propor um cartão postal. Munido de diferentes marmitas trazidas de casa, um grupo de pessoas que não só aquelas a integrar o Programa de Formação, se encontra no mesmo espaço da ação anterior para ocupar a beira da mesma piscina, só que dessa vez rompendo com a fila de maneira marginal.

Como propor um cartão postal recebe reações de incredulidade semelhante a seu antecessor, de modo a evidenciar novamente o desconforto diante do que escapa à normalidade daquele público espontâneo. Como se a noção de um segredo apenas partilhado pelo grupo que almoçava em silêncio simbolizasse um desvio no desejo mais profundo de quem ali estivesse para se autorretratar na paisagem, agora brevemente profanada. Paisagem profanada por um segredo capaz de fraudar as delimitações que institucionalizam uma fila.

Ao refletir sobre o enunciado da proposta, que intui uma instrução, além de um cartão postal a ser reivindicado, a ativação coletiva também convoca o olhar para as negociações entre sujeitos e espaços sob a perspectiva da espetacularização desses territórios. Como propor um cartão postal intenciona em sua partitura uma ação combativa aos regimes hegemônicos que tomam o espaço urbano público como lugar de assimetrias e exclusões.

Tal como nos relatos elaborados para um trabalho numa disciplina na Universidade do Estado do Rio de Janeiro, Matheusa 


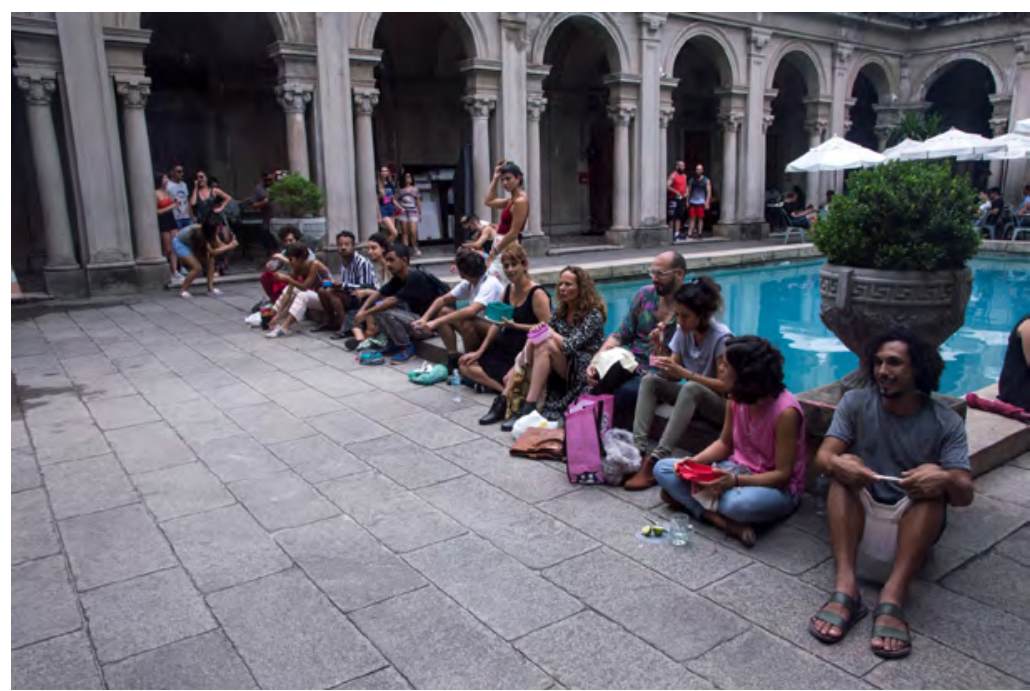

Figuras 3 e 4: Registro da ação Como propor um cartão postal, Alice Ferraro, 2020 Fonte: Acervo do artista.

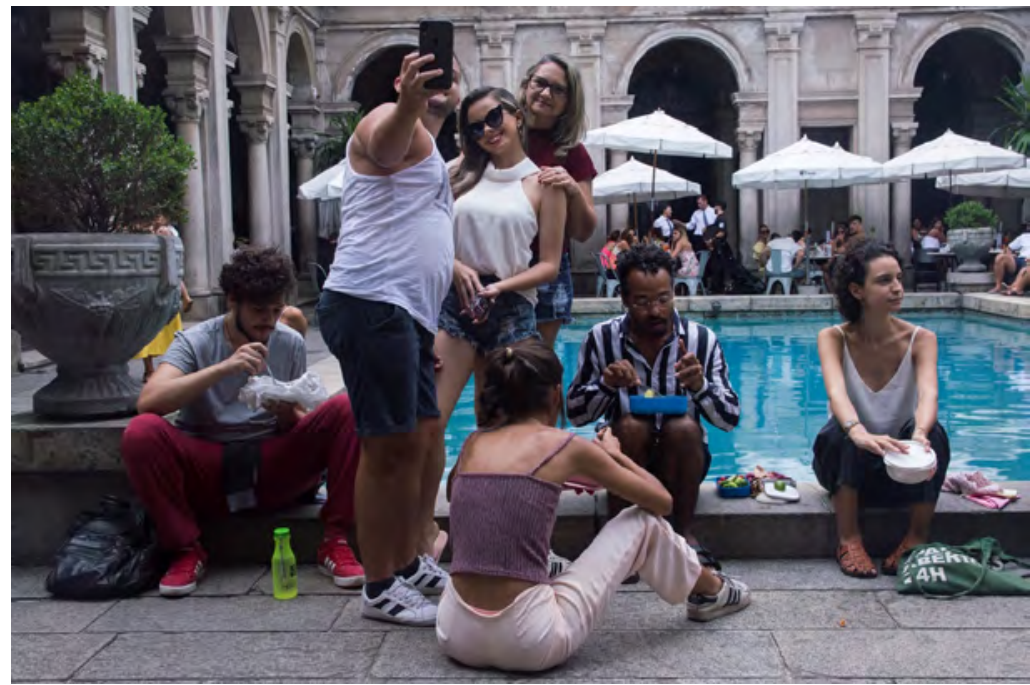

Como propor um cartão postal se propõe a dialogar, entre outras aproximações, com $O$ Rio de janeiro continua lindo e opressor, título dos escritos de Passareli, por denunciar a ausência de suportes básicos para a permanência de sujeitos em espaços que comumente ressaltam marcadores sociais de diferença.

\begin{abstract}
"Me alimentar. Trabalhar para poder estudar. Trabalhar para me alimentar. Ir alimentada para o trabalho. Carregar marmita. Marmita que carrega. Minha marmita leva as comidas que aprendi a fazer através de minha mãe. Minha marmita vai comigo para a faculdade, para o trabalho, para o curso. Rastros de um processo de dedicação e trabalho conjunto para dar estrutura e suporte para as suas filhas. Rastros de um grande processo de exclusão de corpos negros na sociedade/ universidade/cidade. Decidi ocupar o máximo de espaços possíveis, me colocar na cidade para que eu possa me prender nela, agarrar o máximo possível nas estruturas. Como vírus me espalhar pela cidade para me alimentar. Comer o máximo possível, encher a barriga se conseguir" (Idem, p.4).
\end{abstract}

Em Como propor um cartão postal, o imaginário ao qual a marmita alude (esse que revela os rastros de um processo de dedicação e trabalho conjunto) se sobrepõe àquele território como 
uma outra trama. Isso, ao provocar questões que desestruturam discursos fundantes, sugerindo que habitar de maneira não hierárquica e não subalterna esses lugares é, portanto, também uma forma de propor não só um pensamento crítico, mas também uma prática artística como resposta aos regimes citados anteriormente.

Diante disso, a manutenção desse modo de vida perpetuado por um passado aristocrático - o que impediria a confluência de relações não hierarquizadas com os próprios espaços - se faz tão presente e despercebida em certas áreas da cidade que o objeto de estranhamento talvez não seja somente um grupo de pessoas em proposição, e sim algo que escapa ao esperado requinte de um lugar comumente destinado às elites.

Endosso o pensamento trazido até aqui apoiando-me naquilo que aparentemente foi desconsiderado pelos turistas presentes em ambas as propostas que serviram de base para esta escrita. Sem qualquer tipo de cerimônia, faz parte do fundo da maioria das fotografias feitas por visitantes, além da arquitetura eclética do palacete, um segundo grupo de indivíduos consumindo nas dependências de um bistrô que oferece preços não acessados, por exemplo, por quem durante meses reivindicou direitos de permanência naquele mesmo espaço.

Quando passo a perceber que esse primeiro grupo não manifesta a mesma indignação à quantidade de pessoas que usualmente faz suas refeições no bistrô ao fundo, é que me arrisco a concluir que o ponto de incompreensão dessa reflexão seja a marmita enquanto signo. $\mathrm{O}$ incômodo daquele grupo de turistas evidencia que tal signo operou discursivamente de modo a confrontar um estilo de vida ideal, nesse caso, rompendo com essa construção ideológica de uma paisagem que beira a sacralidade.

Como propor um cartão postal reivindica a importância da presença e do coletivo como antídoto ao mal-estar ocasionado pelas cenas que vêm transformando espaços voltados para a arte e para a cultura em espaços essencialmente turísticos. Essa reivindicação também aposta no que há de mais afetivo ao convocar "encontros e encontros entre corpos", como coloca Matheusa Passareli, para um almoço coletivo. Podendo ser entendido como o êxito da "criação de redes de afeto e proteção. Redes de resistência. Resistências afetivas" (Idem, p.2).

Observo que o gesto vai se construindo e se nutrindo em forma de performance, de resistência, de rede. Em forma de mecanismo de confronto à manutenção de estruturas excludentes que fundam instituições e espaços. Trata-se da não-colaboração a "construir essa imagem de cidade espetáculo" (Idem, p.4), recorrendo novamente à Passareli. Como propor um cartão postal convoca o olhar para esse espaço, ainda que temporário, sobreposto à sacralidade dos pontos turísticos, como um "lugar menor que está ao alcance de ser feito dentro das impossibilidades do lugar maior" (BOROWICZ, 2019, p.1).

A ação proposta com as marmitas se deleita, inclusive, no conceito de Lugar Possível, de Duda Borowicz, elaborado e desenvolvido também dentro da Escola de Artes Visuais do Parque Lage. Para Duda, que assim como eu, foi corpo presente no Programa de Formação Gratuito, "o lugar possível é uma tentativa 
de movimento frente às ausências e presenças da instituição" (Ibidem) e se estrutura de modo a investigar a presença coletiva como principal mecanismo de afrontamento e crítica.

O cartão postal a ser proposto em questão existe em intersecção ao Lugar Possível, ambos pretendidos dentro de uma escola que também é ponto turístico, ambos levando em consideração "os deslocamentos percorridos pelos corpos para estarem ali presentes" (Ibidem). Esculpidos no calor das reflexões coletivas em alternativa à manutenção de espaços que ainda enfrentam severas e intencionais dificuldades em lidar com narrativas dissidentes, ambos debruçam-se sobre a "manutenção de vida", também nas palavras de Duda, a operar "sobre a mecânica do desejo, do acaso e de outras forças mágicas"4 (Idem, p.2).

Tanto o supracitado Lugar Possível quanto a prática que envolve almoçar marmitas sobre um cartão postal tocam no trajeto desse grupo que, habitando aquele espaço diariamente, pretendeu romper com a burocratização relacionada ao acesso e permanência aos espaços voltados para a arte. Buscando a comunhão como meio de propor pensamento crítico, instauraram-se ali atitudes da ordem daquilo que é comum e ao mesmo tempo inabitual, como fraudar uma fila e, almoçando onde comumente se esperaria um retrato, interromper toda a simulação envolvida para a construção daquela fotografia.

Seria apropriado, então, apontar que faz parte de uma força mágica, que aqui se anuncia, convocar o outro ao seu território de comunhão? Seria apropriado convocar o outro ao desconforto, como um susto, para que seja possível pensar a partir da imprevisibilidade de gestos tidos como comuns?

Esses questionamentos surgem quando entendo a outridade como processo de reconhecimento do outro enquanto par em potencial. O outro, neste sentido, aparece convocado como o indivíduo em sua maior complexidade, o qual habita simultaneamente uma escola de arte e um ponto turístico, uma exposição dentro de um centro cultural e um ônibus preso ao engarrafamento costumeiro.

Assim, convocar o outro ao seu território de comunhão poderia tratar-se de ofertar um lugar de possibilidades (o Lugar Possível do qual fala Duda Borowicz) para que a desdomesticação dos corpos se dê coletivamente, comprometendo-se com o romper do pensamento individual na sociedade. Além de trazer à discussão, de maneira quase despercebida, as noções de coautoria delegada ao outro, que se vê confrontado e, portanto, convocado a ser mais que mero espectador.

4 Tomando a liberdade da licença poética, o que aqui chamo de magia alude àquilo que não se adapta às práticas do automatismo e da espetacularização dos modelos de cidade e de estilos de vida na contemporaneidade, afetando diretamente a maneira com que a sociedade passa a produzir signos e símbolos. Todavia, escolho tratar neste texto, em interlocução com Duda Borowicz, do verbete magia como uma espécie de imprevisibilidade enquanto força contrária à cultura da autorrepresentação: fator que se mostra indispensável da vida em sociedade, principalmente levando em conta o avanço tecnológico. 


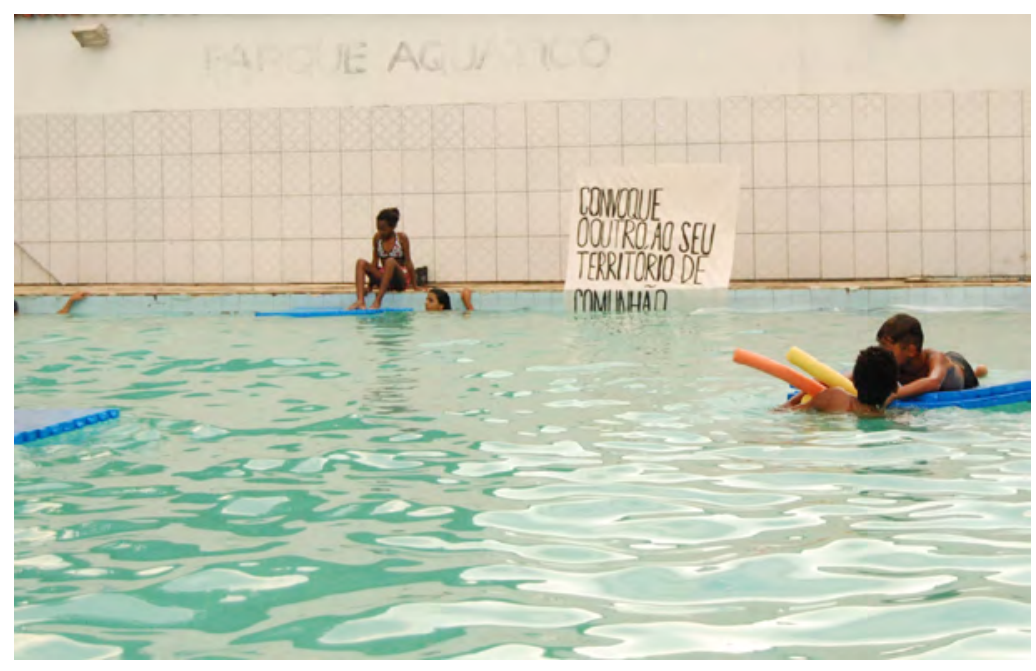

Figura 5: Como propor monumentos, Rafael Amorim, 2019

Fonte: Acervo do artista.

Não coincidentemente tomo emprestado a escrita sobre tecido em outro trabalho de autoria minha. Como propor monumentos (2019) foi exposto num clube de esportes na Baixada Fluminense durante a coletiva Artes Aquáticas: Verão em Queimados, proposta pela Revista Desvio. Retomo a frase para que, de alguma maneira, seja possível criar conexões na pesquisa desenvolvida junto à graduação em artes, buscando reconhecer os terrenos nos quais germinam o pensamento crítico.

A frase convoque o outro ao seu território de comunhão, escrita sobre o tecido parcialmente submerso numa piscina, pretende reforçar a importância de experiências em arte para a partilha de espaços. Sendo imprescindível experienciá-los como espaços de trocas significativas, imantando-os com a complexidade daqueles corpos que ali habitam e a partir de tensionamentos antes não propostos, por não fazerem parte da elaboração de seu projeto arquitetônico ou de sua função primeira.

A presença da piscina como Lugar Possível e de comunhão em ambos os trabalhos não é coincidência: existe aqui uma preocupação ao tratar o pensamento artístico - esse a contar com a imprevisibilidade - que nasce em espaços e/ou situações ditas como não convencionais. Expor um trabalho cuja materialidade conte com seu reflexo na água da piscina de um clube, assim como outro direcionado ao comportamento massivo de turistas numa outra piscina, é também encontrar brechas para que essa discussão alcance as mais diferentes e possíveis fruições no coletivo.

Salvaguarda a evidente diferença de público e espaço entre Queimados e o bairro do Jardim Botânico, Como propor monumentos e Como propor um cartão postal percorrem a ideia de "emergência no mundo" (REZENDE, 2010, p.5). Propõe-se retirar a arte de seu pedestal sublime para multiplicar através de reorganizações dos elementos do cotidiano - no caso, uma piscina de um clube de esportes e marmitas - o pensamento de maneira livre.

A emergência da qual trata Renato Rezende em suas palavras sobre o entendimento dos coletivos que se multiplicaram a partir dos anos 1990 no Brasil ${ }^{5}$ talvez apareça em ambos os trabalhos 
como evocação à imagem de alargamento do mundo como o conhecemos, de modo a diluir as fronteiras entre aqueles binômios citados no início deste estudo. O alargamento dessas noções de mundo, essa força mágica amparada por Duda Borowicz, aparece como que "extrapolando o circuito das artes e se espalhando por diferentes áreas da cultura, transformando as formas de viver, percebendo e definindo conceitos como produção, consumo, arte, entretenimento e política" (Idem, p.9).

Convocar o outro ao seu território de comunhão para propor um cartão postal, semelhante às ideias tanto de Renato, quanto as de Matheusa, de Duda e daquele grupo discente que habitou a EAV, alargaria, assim, algumas ideias calcadas por modelos que se apresentam enrijecidos. Essa convocação à partilha partiria das vozes em consonância, das urgências que perpassam corpos tão diferentes entre si, de estratégias e manobras políticas que são tomadas de posição para outros modos de habitar espaços. Entendendo que, somente após operações semelhantes, os espaços viriam a ser não espaços de arte, mas espaços para a arte.

\section{Para onde ir}

É impossível competir com uma fotografia. Da importância sobre a construção de imagens ao acesso das massas a aparatos fotográficos, daria para elaborar outros estudos pelos quais me interesso em maior ou menor medida para tratar dos discursos teóricos e críticos em trabalhos de arte contemporânea. O que se mostra constantemente dentro desse território movediço que é o viver junto, é justamente o embate com algumas estruturas - físicas e do pensamento - já bem alicerçadas na subjetividade de nós mesmos enquanto indivíduos.

É impossível competir com uma fotografia do Parque Lage, esse registro pensado minunciosamente para a rede social. Há uma performatividade (não percebida) daqueles corpos e sobre a qual também seria de algum interesse discorrer em que nível a mesma influi num comportamento coletivo. O que se mostra constantemente dentro desse território ainda mais movediço, que é a arte, talvez seja, então, a imprevisibilidade da comunhão. Conforme a repercussão com o grupo de turistas diante das ações, viu-se que nem todo público almeja comungar. Assim, a quem interessaria a discussão em arte fora das galerias, centros culturais e museus?

Ainda que impossível competir com o desejo de uma fotografia, Como propor um cartão postal mostrou que existia ali naquela comunhão qualquer coisa de imprevisível para ambos os grupos presentes. A fila, que antes se mantinha à espera, teve sua total dissipação no espaço. Já não havia público sobre quem desferir tal desvio, apenas um encontro entre pessoas. Apenas um almoço compartilhado seguido de um café oferecido àqueles

propriamente dito. Interessa, sim, discutir que tanto a aparição de coletivos no Brasil após os anos 1990 quanto Como propor um cartão postal tentaram operar práticas artísticas atraídas provocadas pelo desejo de friccionarem os ordenamentos normativos do campo social. Tais práticas identificadas por Renato como advindas das vanguardas históricas do início do século XX propunham o questionamento não só do sistema e das instituições de arte, como "dos processos de legitimação e canonização de objetos de arte e de artistas, que passaram a assumir papeis múltiplos" (Idem, p.6). 
corpos, já que os demais turistas, ou aderiam ao grupo em suas fotografias, ou localizavam-se às margens da piscina, também operando seus próprios desvios.

Ainda que incertos os caminhos que a arte e a cultura, também a educação, seguirão no novo e ineficaz modelo de governo que nos presentearam as urnas - também um golpe desferido sobre as tramas coletivas -, tenho comigo que, a partir de Como propor um cartão postal, é possível pensar no agenciamento de lugares imaginários com o intuito de fabular outros usos para os espaços urbanos públicos. O lugar menor construído às impossibilidades do lugar maior.

Tal como os coletivos sobre os quais escreve Renato Rezende, tal qual a matriz de uma outra cidade proposta por Matheusa Passareli, o lugar que é possível existe em resposta às urgências que habitam cada um de nós. É importante reconhecer na possibilidade de dizer "sim" ou "não" ao outro a faísca necessária para fazer tremer as estruturas fundantes que cerceiam qualquer sinal de subjetividade ou dissidência na sociedade.

Escrevo como quem faz um apelo, como quem ainda sente a dificuldade de comungar, como quem vive para buscar meios que auxiliem conexões entre os muitos modos de se estar no mundo. Escrevo como quem narra um grande acontecimento, um importante fato histórico na linha do tempo de uma Escola Livre que ainda sobrevive às machadadas dos golpes diários. Sobretudo, escrevo citando a seriedade com que os meus pares tratam a arte como prática de vida.

Nestas últimas palavras, Keyna Eleison vem ao meu auxílio quando põe em minhas mãos "a Escola como zona." Curadora, crítica e astronauta, (como confessado aos risos em nosso primeiro encontro no Programa de Formação), Keyna discorre sobre a importância de se reconhecer "nas possibilidades que esta língua e este tempo pode nos dar com esta palavra e este termo" (ELEISON, 2019, p.5).

Zona, que é também uma palavra menor para o Lugar Possível "é um local de troca, e para que ela aconteça te-
mos que nos mostrar diversos. Primar pelo dife-
rente sem que necessariamente a diferença se
estabeleça e sim a fome, a fome de assimilar mais
e estar mais em contato com a outra e ser mais
si mesma. Encontro como zona de conhecimento.
Implementação de conhecimento? A questão, as
questões seguem, a partir da presença, do que
fica e do que passa de corpo a corpo" (Ibidem).

Keyna me diz com palavras escritas que "é violento o movimento da descrição de um silêncio, mas nunca inútil e muito menos desnecessário" (Ibidem), e eu escolho acreditar. Acredito, pois, antes de optar pela forma textual, ainda não dimensionava como a escrita poderia ser eficiente para elaborar as reflexões aqui trazidas. Reflexões que, a partir da experiência, deram-se no corpo e que, para cada uma de nós - pessoas habitando o lugar de partilha frente à piscina e pessoas habitando a fila em completo incômodo -, deram-se de maneiras diferentes, mas ainda assim legítimas para ambos os grupos.

É impossível sempre competir com uma imagem, seria uma 
competição violenta e fadada ao fracasso. Tão violenta quanto a descrição de um silêncio, de um almoço. Como então dar volume e dimensionar o que nos coloca em estado de outridade com os nossos - agora entendidos como pares? Resta-nos suspeitar dos lugares que ainda não são zonas de encontros, suspeitar dos lugares que ainda não primam pelo diverso, pelo desvio. Resta-nos sermos agentes de outras matrizes, que se movimentem em silêncio para dilatar o mundo. Sempre em conjunto.

\section{Referências}

BOROWICZ, Duda. Lugar possível. Rio de Janeiro: 2019. Disponível em: $<$ https://drive.google.com/file/d/1rOg88Xh3b2JhXeTr3rph704iwBfsHbAA/ view>

Data de acesso em: 23/03/2020

ELEISON, Keyna. Sobre uma escrita livre presa no papel. In: Catálogo da Exposição final dos alunos do Programa de Formação Deformação EAV Parque Lage 2018. Org. Ulisses Carrilho/Keyna Eleison. dez. 2018. Disponível em: <http://eavparquelage.rj.gov.br/exp-formacao-deformacao/> Data de acesso: 20/03/2020.

PASSARELI, Matheusa. O Rio de Janeiro continua lindo e opressor. Rio de Janeiro: 2017. Disponível em: <https://joaocamillopenna.files.wordpress. com/2018/05/matheusa-o-rio-de-janeiro-continua-lindo.pdf > Data de acesso em: 20/03/2020

REZENDE, Renato. Coleção Circuito: Coletivos. Org. Felipe Scovino/ Renato Rezende. Rio de Janeiro: Editora Circuito, 2010. 